\title{
EDUCAÇÃO SECUNDÁRIA PROFISSIONALIZANTE BRASILEIRA (1909 -1953)
}

\author{
Nilce Vieira Campos Ferreira ${ }^{1}$ \\ Instituto Federal de Educação, Ciência e Tecnologia do Triângulo Mineiro/IFTM - Brasil \\ nilcevieiraura@hotmail.com
}

Recepción: 04/09/2012

Evaluación: 29/09/2012

Aceptación: $15 / 11 / 2012$

Artículo de Revisión

doi: http://dx.doi.org/10.9757/Rhela.19.04

\section{RESUMO}

Este texto contextualiza acontecimentos que antecederam a fundação das escolas técnicas federais brasileiras. Expõe percursos da história do ensino secundário profissionalizante brasileiro. A partir da perspectiva histórica apresenta a escolarização que tem o trabalho como princípio educativo. Encontrou fundamentos no advento da modernidade, enquanto tempo e movimento histórico para o avanço civilizatório e para o desenvolvimento. Objetivou ponderar a escolarização secundária e investigar práticas educativas preconizadas como expressão de historicidade e dos processos de continuidade no seu processo evolutivo. Levantou-se como questionamento quais os rumos que a formação profissionalizante seguiu no Brasil, ponderando fontes escritas documentais e algumas legislações. Ao se

\section{EDUCACIÓN SECUNDARIA PROFESIONAL BRASILERA (1909-1953)}

\section{RESUMEN}

Este trabajo pretende contextualizar los acontecimientos que precedieron a la fundación de las escuelas técnicas federales brasileñas. Expone recorridos de la historia de la enseñanza secun- mapear a trajetória da educação profissional, no período descrito, o que se procurou foi contribuir para o registro da memória das instituições escolares. O surgimento das escolas profissionalizantes federais ocorreu sob o domínio do capital agrário-exportador. Sua consolidação se deu em processos associados à monopolização de saberes elementares pelo Estado e como continuidade do processo de civilização. Os rumos da educação profissionalizante brasileira se firmaram na tradição sendo alimentados pela cultura industrial e por uma ideologia do progresso pelo trabalho.

Palavras-chave: Revista História da Educação Latino-americana, estabelecimento de ensino, escola profissional, Artes e Ofícios.

\section{SECONDARY AND VOCATIONAL EDUCA- TION IN BRAZIL (1909 -1953)}

\section{ABSTRACT}

This text contextualizes the events that preceded the founding of the Brazilian federal technical schools. It exposes history paths from the Brazilian professionalizing secondary teaching.

1 Doutora em Educação pela Universidade Federal de Uberlândia- UFU/MG/BRASIL. Pedagoga no Instituto Federal de Educação, Ciência e Tecnologia do Triângulo Mineiro/IFTM. Integrante do Grupo de Pesquisa em Educação Popular/IFTM-Uberaba (GPEP-IFTM), Núcleo de Pesquisas e Estudos em Educação - IFTM. 
daria profesional brasileña. Desde la perspectiva histórica que explora la escolarización que tiene el trabajo como principio educativo. Encuentra fundamentos en el advenimiento de la modernidad, mientras tiempo y movimiento histórico para el avance de la civilización y el desarrollo. Objetiva ponderar la escolarización secundaria e investigar prácticas educativas defendida como expresión de historicidad y de los procesos de continuidad en el proceso evolutivo. Se plantea como cuestionamiento cuáles las direcciones que la formación profesional siguió en Brasil. La investigación hace uso de escritas documentales. $\mathrm{Al}$ mapearse la trayectoria de la educación profesional en el período descrito, lo que se busca es contribuir a la memoria de registro de las instituciones educativas. Se observa que la aparición de la escuela de formación profesional federal fue bajo la dominación del capital agrario exportador. Su consolidación se llevó a cabo en los procesos asociados a la monopolización de conocimientos elementales por el Estado y como continuidad del proceso de la civilización. Las direcciones de la educación profesional se arraigó en la tradición brasileña siendo alimentados por la cultura industrial y por una ideología del progreso por el trabajo.

Palabras clave: Revista Historia de la Educación Latinoamericana, establecimientos de enseñanza, Escuela profesional, artes y oficios.
From the historical perspective that explores the schooling which has the work as an educational principle. It finds foundations on the advent of modernity, while time and historical movement for the civilizatory advancement and development. Objective to consider the secondary schooling and investigate preconized educational practices as an expression of historicity and of the continuity processes in its evolutionary process. It rises as a questioning what are the directions followed by professionalizing training in Brazil. The research avails of documental written sources. By mapping the professional education trajectory, in the described period, what is sought is to contribute to the memory register of educational institutions. It is observed that the rise of federal professionalizing schools occurred under the dominance of the agrarian-exporter capital. Its consolidation took place in processes associated to monopolization of elementary knowledge by the State and as continuity of the civilization process. The directions of the Brazilian professionalizing education took root in the tradition being fed by the industrial culture and by an ideology of progress by the work.

Key words: Journal of Latin American Education History, educational establishment, vocational school, magazine bistory of the Latin American education.

\section{INTRODUÇÃO}

A formação profissional no Brasil se desenvolveu, desde suas origens, associada ao processo de industrialização na tentativa de adaptar a escola ao mundo da produção. Sua configuração marcou-se por um discurso pedagógico com a intervenção do Estado na instrução da força do trabalho e principal agente pedagógico responsável pelas transformações no campo social e educacional da sociedade brasileira. Esse discurso emergiu consubstanciado por um ensino cujo sentido era o de "disciplinar os desfavorecidos"2.

O recorte histórico aqui exposto fundou-se na crença de que os rumos da educação profissionalizante brasileira basearam-se na tradição da modernidade, alimentada pela cultura industrial e pela ideologia do

2 Celso Suckow Fonseca, História do Ensino Industrial no Brasil. Vol. 1. (Rio de Janeiro: Escola Técnica, 1961), 195. 
progresso que perpassou as matrizes liberais e socialistas de cunho marxista. Nesse discurso progressista, as ideias de escolarização daqueles que estavam na frente governista estiveram intimamente associadas ao advento da sociedade brasileira capitalista moderna em defesa da manutenção do sentido estatal de um sistema público de ensino, laico e gratuito ${ }^{3}$. Para os modernos, havia todo um mundo novo a ser criado e descoberto. $\mathrm{O}$ "questionamento de modelos passados desafiava as noções de tradição e autoridade e implicava uma crença de progresso e desenvolvimento constante da humanidade" .

Nas muitas variações da educação profissional e tecnológica no Brasil ao longo dos anos houve muitas configurações, com especificidades distintas. Dessa forma, a construção da escola pública brasileira se fez de maneira ativa, mas muitas vezes conflitante, apresentando singularidades em sua constituição, o que formou "uma totalidade dinâmica e contraditória sendo mister desenvolver uma investigação sistemática que permita, progressivamente, a reconstrução no plano do conhecimento, das características que se manifestam no desenvolvimento histórico desse objeto: a escola pública brasileira" 5 .

Com isso, as possibilidades de estudos tornaram-se acessíveis como apresentado por Gatti Júnior e Pessanha “o contexto internacional da pesquisa em história e, de modo particular, em história da educação, influencia as temáticas e o percurso da investigação sobre o fenômeno educacional"’6.

\section{Precedentes históricos}

A educação profissional brasileira em sua gênese e travessia se encontrou ligada às transformações sociais, econômicas e políticas que caracterizaram diferentes momentos históricos do país. O ensino profissionalizante foi afetado pelo caráter desenvolvimentista da sociedade brasileira na complexa

Saviani, Demerval, Jane Soares de Almeida et al., O legado educacional do século XIX (Campinas: Autores associados, 2006), 19.

4 Simon Schwartzman, Pobreza, exclusão social e modernidade: uma introdução ao mundo contemporâneo (São Paulo: Augurium, 2004), 11.

Saviani, "O legado educacional do século XIX”, 15.

6 Décio Gatti Júnior y Eurize Pessanha, "História da educaçẫo, instituições e cultura escolar: conceitos, categorias e materiais históricos", En História da educação em perspectiva: ensino, pesquisa, produção e novas investigaçóes, Eds. Décio Gatti Júnior y Geraldo Inácio Filho (Campinas: Autores Associados, 2005), 79. 
relação escola-trabalho, por vezes, indicando que a distinção social e não o trabalho era o princípio educativo. A escolarização secundária surgiu como um processo associado à monopolização de saberes elementares pelo Estado numa "escola produzida como a instituição capaz não apenas de instruir e educar a infância e a juventude, mas de produzir um país ordeiro, progressista e civilizado"7. No início do século XIX a escola foi encarada como fator civilizatório, como instrumento de ordem e progresso da sociedade "capaz de garantir, mediante extensão da educação moral e instrução elementar à população livre, condições de governabilidade. [...] faz-se necessário a constituição de estratégias de ordenamento social, para o qual a educação seria um instrumento eficaz"s.

A educação era vista como instrumento de ordenamento, reconstrução social e estabilidade política. Havia a crença de que por meio da massificação da educação o país alcançaria o sonhado progresso, sendo a ela reservada uma das tarefas mais importantes no projeto de reconstrução social: a busca da homogeneização. Como a educação era considerada elemento necessário para a constituição da sociedade moderna, deveria ser um processo democrático. Nessa conjuntura, a superestrutura ideológica era anacrônica e transpunha a expansão das forças produtivas ${ }^{9}$. O contexto da educação secundária brasileira enquanto tempo e movimento histórico marcava-se pelo desejo desenvolvimentista com sentidos comuns entre o social, o material e o cultural, estruturado na referência Estado-nação. Perpassava por ela "tendências e orientações de sentido contrário e por alguns paradoxos, designadamente na difícil e impossível conciliação entre liberdade e institucionalização, nas suas variantes de formalização, regulação normalização ${ }^{10}$ ". A educação pelo trabalho se tornaria o princípio educativo como "a ótica do ensino de ofícios, ministrado para o artesanato, a manufatura e a indústria, de modo cada vez mais escolarizado, se não de fato, ao menos projetado" 11 . Dessa forma, se articularia ao processo de escolarização e à defesa da necessidade de modernização.

Luciano Mendes de Faria Filho, Dos pardieiros aos palácios: cultura escolar e urbana em Belo Horizonte na Primeira República (Passo Fundo: UPF, 2002), 24.

8 Cintia Greive Veiga, História da Educação (São Paulo: Ática, 2008), 202.

9 Caio Prado Júnior, História econômica do Brasil (São Paulo: Brasiliense, 1982), 209.

10 Justino Magalhães, "A história das Instituições Educacionais em perspectiva”, em História da educação em perspectiva: ensino, pesquisa, produção e novas investigaçōes. Eds. Décio Gatti Júnior y Geraldo Inácio Filho (Campinas: Autores Associados, 2005), 79.

11 Luís Antônio Cunha, O ensino profissional na irradiação do industrialismo (São Paulo: Flacso, 2000), 9. 
O ideário, trabalho e educação, era fruto de relações sociais concretas, nascidas no desígnio imperioso de se tornar o Brasil civilizado consoante os padrões europeus. Identificado com a modernidade, o novo formato escolar encontrava fundamentos na lei econômica da divisão do trabalho percebida pelos reformadores e educadores da instrução pública na época. A visão que se tinha era a de uma "escola produzida como a instituição capaz não apenas de instruir e educar a infância e a juventude, mas de produzir um país ordeiro, progressista e civilizado" ${ }^{12}$.

Essa noção era coerente com as estruturas de um mundo moderno que se organizava, sobretudo, em tono dos processos de civilização (com Elias), de racionalização (com Weber), de institucionalização (com Focault) da vida social no seu conjunto, em um estilo de vida radicalmente novo, ou seja, o Estado era "entendido como poder exercido por um centro, segundo um modelo de eficiência racional e produtiva, em aberto contrate com o exercício de outros poderes (eclesiástico, aristocrático) e com a sobrevivência da desordem dos marginalizados (pobres, criminosos, etc.)"13.

Esse modelo de Estado burocrático com exercício centralizado de poder ocorreu em países da Europa com elementos que delinearam o nascimento de um novo tipo de Estado, o Estado moderno, com requisitos de controlador social e produtor de leis impositivas à comunidade, permanecendo como protagonista central no itinerário histórico da Modernidade. Desenvolveu-se no Brasil marcado sobremaneira pelas inúmeras reformas do ensino brasileiro.

\section{Reformas do ensino brasileiro}

Em busca de uma educação liberal e laica, no contexto iluminista, no Brasil não havia sentido em se atrelar educação e religião aos interesses de uma classe, pois o movimento trazia como pressuposto a educação ao encargo do Estado; a obrigatoriedade e gratuidade do ensino elementar; o nacionalismo como recusa ao universalismo jesuítico; a ênfase nas línguas vernáculas e orientação prática voltada para as ciências, técnicas e ofícios, não mais privilegiando o estudo exclusivamente humanístico ${ }^{14}$.

\footnotetext{
Faria. Dos pardieiros aos palácios, 24.

Franco Cambi, História da pedagogia (São Paulo: UNESP, 1999), 200.

María Lúcia Aranha, História da Educação e da Pedagogia, geral e do Brasil (São Paulo: Moderna, 2008), 174.
} 
Com a ordem de expulsão dos jesuítas do Brasil, em função de radicais diferenças de objetivos, pois a educação das escolas da Companhia de Jesus tinha por objetivo servir aos interesses da fé e a reforma preconizada por Pombal visava uma educação laica e controlada pelo Estado, o Marquês de Pombal, gestor da introdução das ideias iluministas, tentou organizar a escola para servir aos interesses do Estado. Com a ruptura histórica de um processo já implantado e consolidado como modelo educacional, pouca coisa restou de prática educativa no Brasil, uma vez que os jesuítas levaram consigo sua organização pedagógica. O ensino jesuítico então implantado se constituiu para "a versão da educação pública religiosa [...] podia ser considerado como público por ser mantido com recursos públicos e pelo seu caráter de ensino coletivo" ${ }^{15}$.

Contrapondo-se às ideias religiosas, fundados nas ideias laicas inspiradas no Iluminismo, com o governo assumindo a instrução, o Estado brasileiro emergiu com a responsabilidade limitada ao pagamento do salário do professor e às diretrizes curriculares da matéria a ser ensinada. Cabia ao professor prover as condições materiais relativas ao local, geralmente sua própria casa, e sua infraestrutura, assim como os recursos pedagógicos a serem utilizados no desenvolvimento do ensino ${ }^{16 .}$

Essa situação somente sofreu efetiva mudança com a Proclamação da República, quando os ideais positivistas se aproximam do pensamen-to republicano e "sob a égide dos estados federados, a escola pública, entendida em sentido próprio, fez-se presente na história da educação brasileira"17.

Nas primeiras décadas do século XIX, o projeto liberal se alimentou do nacionalismo presente no universo político e social, com o lema "É preciso Educar o povo!". Para as elites dirigentes, a educação consistia no instrumento de formação do cidadão republicano. Configurações de educação em vigor no Brasil que partiam da concepção liberal tomaram conta do pensamento e da política educacional do período. Diversas práticas educativas tornaram-se instrumento de moralização e de civilização do povo como "vitória das luzes e da razão sobre as trevas e a ignorância, alicerce

\footnotetext{
Demerval Saviani, et. al., O legado educacional do século XX (Campinas: Autores associados, 2004), 16.

Saviani, O legado educacional do século XX, 16-17.

Saviani, O legado educacional do século XX, 16.
} 
das sociedades modernas, garantia de paz, de liberdade, da ordem e do progresso social; de regeneração da nação"18.

O elevado percentual de analfabetos no ano de 1900, com a exigência de saber ler e escrever como condição para a promoção de cargos políticos e administrativos, exigiu a 'reordenação' da escola para atender às novas exigências e necessidades da sociedade moderna industrial fundada no trabalho livre. A educação das massas ocupou lugar central nas propostas das diversas reformas ${ }^{19}$. O processo de modernização geral da sociedade brasileira envolveu educadores que se organizaram, discutiram e formularam propostas pedagógicas e, pela primeira vez, constituíram-se em categoria profissional autônoma. Os anos de 1920 foram marcados pelo confronto de ideias entre correntes divergentes, influenciadas pelos movimentos europeus e pela crise econômica mundial de 1929. A partir daí, "a pedagogia brasileira compartilha do movimento da Modernidade Europeia, com descompassos, mas se inserindo e participando de seu andamento" ${ }^{20}$.

Com base nesses movimentos, em 1930, foi criado o Ministério da Educação e Saúde Pública e, em 1931, o governo provisório sancionou decretos organizando o ensino secundário e as universidades brasileiras. Esses decretos foram preconizados pelas reformas do ministro Francisco Campos. Na sequência, uma série de medidas governamentais proliferou e a educação começou a ser reconhecida, no plano institucional, como uma questão nacional ${ }^{21}$.

Nesse período, a sociedade brasileira economicamente se fundamentava no desenvolvimento do processo de industrialização que contribuía para modificar os grupos da sociedade brasileira. As ideias capitalistas de modernização do início do Século XX tomavam forma no Brasil, mas

18 Rosa Fátima de Souza, Templos de Civilização: a implantação da escola primária graduada no Estado de São Paulo (1890/1910) (São Paulo: EDUNESP, 1998), 26.

19 Wenceslau Gonçalves Neto y Carlos Henrique Carvalho, "O nascimento da educaçáo republicana: princípios educacionais nos regulamentos de Minas Gerais e Uberabinha (MG) no final do Século XIX”, em História da educação em perspectiva: ensino, pesquisa, produção e novas investigaçôes, Eds. Décio Gatti y Geraldo Inácio Filho (Campinas: Autores Associados, 2005), 264.

20 José Carlos Souza de Araújo, "Marcos filosóficos da modernidade em torno da educação da criança: antropologias da infância em disputa?" em A infância na modernidade: entre a educação e o trabalho, Eds. José Carlos Sousa de Araújo, Carlos Henrique de Carvalho y Esmeralda Blanco Bolsonaro de Moura. (Uberlândia: EDUFU, 2007), 182-183.

21 Saviani, "O legado educacional do século XX", 19. 
continuavam ligadas à ideia de povoamento, civilização $\mathrm{O}^{22}$ e melhoria do país. O posicionamento ideológico conservador em relação à educação era de que às escolas cabia a preparação do homem de acordo com sua posição social ${ }^{23}$, a fim de que desempenhasse suas funções de cidadão, desenvolvesse seu senso de moralidade e a formação de um bom caráter. Valores sociais surgiram e foram incorporados, frutos da dinamicidade implantada pelas modificações econômicas e das novas relações que se estabeleceram na dinâmica social, considerando as conjunturas sociais que surgiram e, "no bojo das transformações vai se destacando o novo sistema de valores da civilização urbano-industrial" ${ }^{24}$.

A presença da Modernidade se revelou por meio de apropriações, disseminações e ressignificações desses valores. A educação se colocava com a missão de conter as ameaças à ordem social, entre elas, a ignorância do povo. Esse discurso era evidenciado nos currículos, na metodologia, nas reformas educacionais baseadas na cultura e nos padrões da classe dominante. Predominava a visão de educação como “[...] uma arma poderosa de mistificação e de conservação entre as mãos da classe capitalista. Tem tendência para dar aos jovens uma educação que os torna leais e resignados ao sistema atual, e os impede de descobrir as suas contradições internas" ${ }^{25}$.

Pensada dessa forma, a educação brasileira reforçou um caráter dual: uma educação acadêmica pensada para as elites governantes e uma educação profissionalizante destinada à imensa massa trabalhadora, os operários. O ensino secundário profissionalizante deveria possibilitar aos jovens uma formação que os habituasse à vida social e profissional concernente com as exigências da civilização na sociedade brasileira moderna e coerente com as propostas de reforma preconizadas pelo Estado. Ao ensino profissionalizante coube o encargo de torná-los capazes de atuar produtivamente na vida em sociedade. A escola tornava-se responsável pelo ensino de ofícios necessário ao meio social no qual os sujeitos escolares estavam inseridos se mostrou como um artefato de controle social, destinado a disciplinar as classes populares, pela introjeção do amor ao trabalho e a civilização dos costumes ${ }^{26}$.

\footnotetext{
Veiga, "História da educaçâo", 202.

Veiga, "História da Educação", 178.

Jorge Nagle, Educação e sociedade na primeira república (São Paulo: EPU, 1976), 23.

Marx, et al., Crítica da Educação e do Ensino (Lisboa: Moraes Editores, 1978), 37.

Veiga, "História da Educação", 178.
} 
Com a desigualdade de conhecimentos se perpetuou a desigualdade social. As décadas de 1940 e 1950 sinalizaram tal fato e a educação brasileira foi moldada com o objetivo de manutenção e reprodução dessas desigualdades. Nesse contexto, acentuou-se no Estado brasileiro, a noção de que havia necessidade de institucionalização de uma "educação para o desenvolvimento" ${ }^{27}$. Isto é, um ensino técnico profissionalizante com a finalidade de educar para o trabalho, que não deveria ocorrer apenas ao nível de ensino médio, mas até mesmo no ensino primário e superior.

A grande preocupação dessas décadas para o Estado e suas reformas educacionais era o ensino profissionalizante e a educação para o trabalho, em virtude de o Estado se encontrar sob a tutela do mercado e do capital. O Estado inverteu, assim, o papel da educação e colocou a escola sob os desígnios diretos do mercado, como formadora de mão-de-obra. As reformas, dessa época, mantiveram, sob a égide da modernidade, a conservação da dominação, pois o grau de desenvolvimento urbano passou a ser medido pela capacidade de "a cidade atender e ao mesmo tempo orientar necessidades humanas fundamentais com base na expansão do capitalismo industrial: habitação, trabalho, locomoção, educação" ${ }^{28}$.

Os reflexos da economia e a influência do capitalismo e das ideias liberais permeavam os conflitos educacionais. Atrelada aos interesses do Estado e aos ditames do mercado, a escola pública exercia uma função importante como reguladora da luta de classes e da ordem social ${ }^{29}$. Pela escolarização perpassava o intuito principal de efetivar o interesse de classes hegemônicas "com marcas de disputas e acordos" foi mantida estreitamente vinculada ao Estado que dispunha de força para manter a ordem das coisas. Esses princípios foram impostos à consciência dos indivíduos por meio da escolarização que representou uma parte essencial da ação persuasiva e preventiva do Estado brasileiro.

Prado Júnior, "História econômica", 209

Cynthia Greive Veiga, "Escola Nova: a invenção de tempos, espaços e sujeitos”, em Liçôes de Minas: 70 anos da Secretaria de Educação, Eds. Faria Filho, Luciano Mendes de Peixoto, Ana Maria Casasanta (Belo Horizonte: Secretaria de Estado da Educação de Minas Gerais, 2003), 37.

29 Faria, "Dos pardieiros aos palácios", 58

30 Gatti, "História da educação”, 86. 


\section{O ensino profissionalizante}

A formação profissional brasileira foi reservada aos "menos favorecidos"31. A educação brasileira estabelecia nítida distinção entre aqueles que detinham o saber - ensino secundário, normal e superior, e os que executavam tarefas manuais - ensino profissional. A concepção do trabalho associado a esforço físico advinha da ideia e vivência da escravidão que reforçou a distinção, deixando marcas profundas e preconceituosas para quem executava trabalho manual. Índios e os escravos foram os primeiros aprendizes de oficio no Brasil. Esses primeiros momentos marcaram com um estigma de servidão o início do ensino industrial em nosso país.

"Desde então, habituou-se o povo de nossa terra a ver aquela forma de ensino como destinada somente a elementos das mais baixas categorias sociais" 32 . Por muito tempo a herança colonial escravista influenciou pejorativamente as relações sociais no Brasil, bem como a visão da sociedade a respeito de educação e formação profissional. O desenvolvimento intelectual era visto como desnecessário para a maior parte da população. A baixa escolaridade da massa trabalhadora não era considerada entrave significativo à expansão econômica. Esses fatores não só agravaram o pensamento generalizado de que os ofícios eram destinados aos "miseráveis e deserdados da sorte", como impediu, pela feição econômica de que se revestia, aos trabalhadores livres exercerem certas profissões procedendo "dos primeiros tempos de nossa civilização a mentalidade de desprezo pelos trabalhos que requerem o uso das mãos" ${ }^{\prime 3}$.

As artes mecânicas e as manufaturas acabaram não exercendo atração para os que podiam escolher. Isto é, para os que eram livres, para aqueles que não eram escravos, os que, mesmo explorados na venda de seu trabalho, não eram compelidos a ele por coação física, mas por mecanismos sociais de formação da força de trabalho dentro do modo de produção capitalista. A educação profissional destinava-se a "ensinar ofícios a crianças e jovens que não tivessem escolha. [...] aos delinquentes"34. Nessa perspec-

\footnotetext{
31 Franco, Luiz Antônio Carvalho y Sidnei Sauerbronn, "Breve história da formação profissional no Brasil” (São Paulo, CENAFOR, 1984), 71.

Fonseca, História do ensino industrial, 15.

Fonseca, História do ensino industrial, 16.

Cunha, O ensino profissional na irradiação do industrialismo, 6.
} 
tiva o ensino secundário profissionalizante brasileiro foi oferecido a quem não podia opor resistência a um ensino que preparava para ocupações socialmente definidas como de menor importância.

\section{Escolas de aprendizes artífices}

Com a consolidação do Regime Republicano, a circulação intensa das ideias de progresso, modernidade e ordem social avançou. Com os postulados positivistas permeando as discussões centralizadas na educação como artifício essencial nos investimentos sociais, em 1909 o Presidente Nilo Peçanha instalou dezenove "Escolas de Aprendizes Artífices" destinadas "aos pobres e humildes" ${ }^{35}$, distribuídas em várias Unidades da Federação pelo Decreto 7.566, de 23 de setembro de 1909.

"Art. 1". Em cada uma das capitaes dos Estados da Republica o Governo Federal manterá, por intermédio do Ministério da Agricultura, Indústria e Commercio, uma Escola de Aprendizes Artifices, destinada ao ensino profissional primario gratuito" ${ }^{36}$.

A justificativa para a criação desse conjunto de Escolas de Aprendizes Artífices era a necessidade de prover as classes proletárias de meios que garantissem a sua sobrevivência. Essas escolas foram instaladas, uma em cada capital federativa brasileira, a exceção de duas que não foram situadas nas capitais, a de Campos, no Estado do Rio de Janeiro, e a de Pelotas, no Estado do Rio Grande do Sul. Essas escolas deveriam prover os "desfavorecidos da fortuna" de "hábitos de trabalho profícuo", sendo dever do governo "formar cidadãos úteis", expressões contidas no Decreto n ${ }^{\circ} 7.566$.
"Considerando: que o aumento constante da população das cidades exige que se facilitem às classes operárias os meios de vencer as dificuldades sempre crescentes da luta pela exis- tência; que para isso se torna necessário, não só habilitar os filhos dos desfavorecidos da fortuna com o indispensável preparo técnico e intelectual, como fazêe-los adquirir hábitos de trabalho proficuo, que os afastará da ociosidade, escola do vício e do crime; que é um dos primeiros deveres do Governo da República formar cidadãos úteis à Nação" ${ }^{37}$ (grifos nossos).

A criação dessas escolas, que possuíam um caráter terminal e não se articulavam com os demais graus de ensino, formalizou a dualidade es-

\footnotetext{
Brasil, Decreto Lei no 7.566 de 23 de setembro de 1909.

Brasil, Decreto Lei no 7.566 de 23 de setembro de 1909.

Brasil, Decreto Lei no 7.566 de 23 de setembro de 1909.
} 
trutural entre ensino acadêmico e ensino profissionalizante que perdurou até os dias atuais. Reforçando a dualidade escolar ${ }^{38}$, o Estado Novo brasileiro erigiu uma arquitetura educacional que ressaltava a sintonia entre a divisão social do trabalho e a estrutura escola. Emergiu o ensino secundário destinado às "elites condutoras" e os ramos profissionais do ensino médio destinados às "classes menos favorecidas". Mesmo para o ensino profissionalizante os alunos deveriam ser selecionados e, "a pobreza, ou menor favorecimento poderia ser condição conjuntural, mas não era suficiente para ingresso num curso profissional" 39 . As escolas se tornaram responsáveis pela organização do ensino profissionalizante industrial, pois "as exigências acarretadas pelo próprio processo produtivo, tanto na indústria quanto nos transportes ferroviários, passaram a exigir trabalhadores dotados de qualidades que não poderiam resultar de processos aleatórios" ${ }^{\prime 40}$. Os anos de 1920 e toda a década de 1930 assistiram a uma importante mudança nos destinatários do ensino profissional. A Câmara dos Deputados promoveu uma série de debates sobre a expansão do ensino profissional e propôs a extensão a todos, pobre e rica, e não apenas aos "desafortunados" ${ }^{41}$.

O processo de industrialização e urbanização da sociedade brasileira levou os educadores a discutirem a modernização da educação nacional como um todo. Destacaram-se neste movimento Fernando de Azevedo, Anísio Teixeira e Lourenço Filho que defendiam uma ação progressista, contrária à educação até então existente no Brasil, considerada elitista, jesuítica e autoritária. Esses idealistas acreditavam no progresso econômico e não confiavam que o capital industrial "pudesse ser atropelado pelo capital financeiro monopolista, produzindo graves desequilíbrios socioeconômicos, isto é, ao lado do polo tecnológico altamente desenvolvido, causando imensos bolsões de miséria" ${ }^{42}$.

Esse grupo de educadores brasileiros imbuídos de ideias inovadoras em matéria de educação fez com que a discussão também se voltasse para o ensino profissionalizante, com o objetivo de melhor atender a demanda das indústrias. Como consequência, no final dos anos 1920 e início dos

\footnotetext{
Cunha, O ensino profissional na irradiação do industrialismo, 7.

Cunha, $O$ ensino profissional na irradiação do industrialismo, 6.

Cunha, O ensino profissional na irradiação do industrialismo, 6.

Cunha, O ensino profissional na irradiação do industrialismo, 34.

42 Ester Buffa y Paolo Nosella, Educação negada: introdução ao estudo da educação brasileira contemporânea (São Paulo: Cortez, 1991), 65.
} 
anos 1930 "o ensino profissionalizante esteve presente na maioria das legislações estaduais com oferta de cursos públicos ou particulares para o comércio e a indústria e escolas profissionais secundárias" ${ }^{43}$.

A criação do Conselho Nacional de Educação se deu em 1931, Nesse mesmo ano foi efetivada a reforma educacional, conhecida pelo nome do Ministro Francisco Campos, que prevaleceu até $1942^{44}$. Os destaques da reforma Francisco Campos foram os Decretos Federais n ${ }^{\circ}$ 19.890/31 e 21.241/32 que regulamentaram a organização do ensino secundário; o Decreto Federal n. ${ }^{\circ}$ 20.158/31, organizou o ensino profissional comercial e regulamentou a profissão de contador. A importância deste último se deve ao fato de ser o primeiro instrumento legal a estruturar um curso incluindo a ideia de itinerários de profissionalização ${ }^{45}$.

"O ensino comercial foi reorganizado (decreto 20.158 de 30 de junho [1931]), sendo instituido como um sistema paralelo, tendo um grau pós-primário, um técnico e um superior. Para os portadores de certificados de conclusão da escola primária havia, no ensino comercial, a possibilidade de ingresso no curso de auxiliar de comércio (dois anos) ou no curso propedêutico (três anos). Este constituindo condição, ao lado do curso secundário, para ingresso nos cursos técnicos (um a três anos), compreendendo as seguintes modalidades: secretário, guarda-livros, administrador-vendedor, atuário e perito-contador" ${ }^{46}$.

O Manifesto dos Pioneiros da Educação Nova de 1932 trouxe a possibilidade de organização de uma escola democrática que proporcionasse as mesmas oportunidades para todos. $\mathrm{O}$ ensino fundado em uma cultura geral comum, de forma flexível, possibilitaria especializações "para a atividade de preferência intelectual (humanidades e ciências) ou de preponderância manual e mecânica (cursos de caráter técnico)". As especificações foram assim agrupadas: a) extração de matérias primas (agricultura, minas e pesca); b) elaboração de matérias primas (indústria); c) distribuição de produtos elaborados (transportes e comércio) ${ }^{47}$. Com a promulgação da Constituição de 1937, contudo, muito do que fora definido em matéria de educação foi abandonado. Entretanto, pela primeira vez, uma Constituição brasileira tratou das escolas vocacionais e pré-vocacionais, como um dever do Estado para com as classes menos favorecidas, como expressas no Art. 129.

\footnotetext{
Veiga, História da educação, 252.

Veiga, Escola Nova, 53.

Cunha, O ensino profissional na irradiação do industrialismo, 21.

Cunha, O ensino profissional na irradiação do industrialismo, 22.

Franco, Breve história da formação, 74.
} 
"Art. 129. O ensino pré-vocacional e profissional destinado às classes menos favorecidas é, em matéria de educação, o primeiro dever do estado. Cumpre-lhe dar execução a esse dever, fundando institutos de ensino profissional e subsidiando os de iniciativa dos Estados, dos Municípios e dos indivíduos on associacões particulares e profissionais".

Essa obrigação do Estado com as classes menos favorecidas seria cumprida com "a colaboração das indústrias e dos sindicatos econômicos", as chamadas "classes produtoras", que deveriam "criar, na esfera de sua especialidade, escolas de aprendizes, destinadas aos filhos de seus operários ou de seus associados" ${ }^{\text {"48 }}$. Constituía uma demanda do processo de industrialização desencadeado na década de 1930 que exigia maiores e crescentes contingentes de profissionais especializados para a indústria, o comércio e os serviços.

A Reforma Capanema, a partir de 1942, compôs o ensino com cinco anos de curso primário, quatro de curso ginasial e três de colegial, este último podendo ser ofertado na modalidade clássico ou científico. O ensino colegial perdeu o caráter propedêutico, preparatório para o ensino superior e passou a se preocupar com a formação geral. Foi composta pelos seguintes Decretos-lei: a) 1942 - Leis Orgânicas do Ensino Secundário (Decreto-Lei n. ${ }^{\circ}$ 4.244/ 42) e do Ensino Industrial (Decreto-Lei n. ${ }^{\circ}$ 4.073/42); b) 1943 - Lei Orgânica do Ensino Comercial (Decreto-Lei n. ${ }^{\circ}$ 6.141/43); c) 1946 - Leis Orgânicas do Ensino Primário (Decreto-Lei n. ${ }^{\circ} 8.529 / 46$ ), do Ensino Normal (Decreto-Lei n. ${ }^{\circ} 8.530 / 46$ ) e do Ensino Agrícola (Decreto-Lei n. ${ }^{\circ}$ 9.613/46). A prioridade dada à reforma do ensino secundário foi uma ocasião propícia para a reafirmação dos princípios mais gerais da concepção educacional do ministério Capanema ${ }^{49}$.

No conjunto das Leis Orgânicas da Educação Nacional, o objetivo do ensino secundário e normal era o de "formar as elites condutoras do país". Já o objetivo do ensino profissional era o de oferecer "formação adequada aos filhos dos operários, aos desvalidos da sorte e aos menos afortunados, aqueles que necessitam ingressar precocemente na força de trabalho". A herança dualista perdurava e era explícita. A política educacional do Estado Novo "ressaltava a sintonia entre a divisão social do trabalho e a estrutura

48 Cunha, O ensino profissional na irradiação do industrialismo, 28.

49 Simon Schwartzman, Bomeny, Helena Maria Bousquet, y Vanda Maria Ribeiro Costa, Tempos de Capanema (São Paulo: Paz e Terra, 2000), 245. 
escolar, entre ensino secundário, destinado às elites condutoras e os ramos profissionais do ensino médio" 50 . Cada uma dessas leis se referia à articulação dos ramos de ensino considerados ao ensino superior e até então não era possível aos concluintes do curso secundário candidatar aos exames vestibulares. Mesmo depois dessas leis o acesso ao acesso ao ensino superior ainda foi muito restrito.

A Lei Orgânica do Ensino Industrial estabeleceu que os alunos do secundário podiam se inscrever em cursos do último ciclo do ensino regulado por aquela Lei, mas o inverso não ocorria ${ }^{51}$, pois aos egressos do primeiro ciclo industrial não era permitido se matricularem nos cursos científicos.

\section{"Em 1950, era corrigida, sendo permitido àqueles estudantes o ingresso no segundo ciclo do ensino secundário, desde que completassem o estudo das disciplinas em que diferiam os dois currículos. [...] A Lei da Equivalência, surgida em 1953, viria ampliar ainda mais as conquistas conseguidas, pois articulava o ensino industrial com qualquer escola superior, ao invés de fazê-lo somente com as de engenharia, como ficara determinado antes $" 52$.}

Foi somente com a Lei Federal n. ${ }^{\circ} 1.821 / 53$ que se passou a permitir a equivalência entre os estudos acadêmicos e profissionalizantes, quebrando a rigidez do próprio ensino profissional, consolidado pela Lei Federal n. ${ }^{\circ}$ 1.076/50. A Lei Federal n. $.^{\circ} 1.821 / 53$ dispunha sobre as regras para a aplicação desse regime de equivalência entre os diversos cursos de grau médio e sua regulamentação ocorreu com o Decreto n. ${ }^{\circ} 34.330 / 53$, produzindo seus efeitos somente a partir do ano de 1954. Mesmo após a promulgação da Lei de Diretrizes e bases da Educação Nacional, em 1961, a dualidade estrutural persistia, muito embora houvesse a garantia de passagem entre o ensino profissionalizante e o secundário ${ }^{53}$.

Com o passar dos anos, novas tecnologias foram exigindo mão-deobra cada vez mais qualificada. Várias famílias que moravam em zonas rurais migraram para os centros urbanos, uma vez que a economia, até então predominantemente agrícola, passou a concentrar suas atividades no comércio e na indústria, surgindo uma nova feição para o ensino in

\footnotetext{
Cunha, O ensino profissional na irradiação do industrialismo, 7.

Silvia Manfredi, Educação Profissional no Brasil (São Paulo: Cortez, 2002),62.

Fonseca, "História do ensino industrial", 665.

Manfredi, Educação profissional, 62.
} 
dustrial. Ao ensino não cabia apenas a instrução da juventude destinada às fábricas, ensinando-lhe um ofício, mas também a formação humana e cidadã de modo a ajustá-la à sociedade ${ }^{54}$. A formação profissional destinada aos jovens brasileiros estabeleceu íntima relação entre educação e afazeres, típicas da relação economia e trabalho da sociedade capitalista da época.

\section{CONSIDERAÇÕES}

Um amplo projeto civilizatório foi idealizado no Brasil e a educação foi considerada frente imprescindível desse projeto. No período de 1909 a 1950, o ensino brasileiro se caracterizou como uma proposta educacional dualista, pois oferecia escola diferenciada aos aprendizes nos ensinos propedêutico e profissional. No início, a educação profissional objetivou instrumentalizar a população, ensinando-a a ler e a escrever, numa concepção de educação como ferramenta destinada, num amplo processo civilizatório, aos desvalidos da sorte. Visava também prover as classes trabalhadoras de ocupações manuais e mecânicas como forma de sobrevivência, nos padrões de uma educação cívico-patriótica.

A industrialização, a urbanização, o avanço tecnológico e o desenvolvimento econômico reforçaram a necessidade de escolarização dos brasileiros fosse para cumprir determinados interesses do Estado, atender ao mercado, aprimorar conhecimentos, ou para a obtenção de um diploma atestando certo grau de escolarização. Prevaleceu, no caso brasileiro, políticas públicas emanadas do Estado centralizadas na dualidade entre uma educação para o trabalho, para os desfavorecidos, que precisam encarar o mercado de trabalho quando ainda jovens, e outra educação propedêutica para possibilitar graus mais elevados de estudo, designada à elite, aos bemnascidos, aos bem-sucedidos. Essa situação começou a ser superada nos anos de 1950, marcados por interesses de grupos específicos, revelada nas ações e tomadas de posições da elite intelectual do país. Essa elite elaborou um projeto educacional que via na educação um elemento de disseminação cultural e de mudança de mentalidades, cujos anseios de "modernidade" constituíram o eixo central para a construção de uma sociedade brasileira educada.

54 Wenceslau Gonçalves Neto, Estado e agricultura no Brasil ( São Paulo: Hucitec, 1997), 35. 
Seguindo as orientações das políticas nacionais, contudo, o ensino profissionalizante adentrou a contemporaneidade reforçando os princípios historicamente constituídos na Modernidade, mas ainda não incorporando parcelas significativas da população brasileira. $\mathrm{O}$ ensino profissionalizante foi moldado de acordo com a realidade e as necessidades do Estado-Nação. Nessa visão, ao ensino caberia o preparo para a vida profissional, pois o aperfeiçoamento do trabalho representava um dos principais apoios para a prosperidade pública.

O surgimento das escolas profissionalizantes federais ocorreu sob o domínio do capital agrário-exportador e se consolidou firmada em processos associados à monopolização de saberes elementares pelo Estado, como continuidade do processo de civilização. Os rumos do ensino secundário profissionalizante brasileiro se firmaram na tradição sendo alimentados pela cultura industrial e por uma ideologia do progresso pelo trabalho.

A garantia constitucional da educação como um bem da civilização, indispensável para a cidadania não se concretizou de todo e esses impasses ainda perduram. O ensino profissionalizante secundário tornou-se um instrumento a favor da civilização com o intuito de preparar os alunos para o desempenho de ofícios práticos cujo escopo era preparar para as ocupações relacionadas à produção. Essas orientações influenciaram sobremaneira os rumos da educação profissionalizante no Brasil.

\section{REFERÊNCIAS}

Aranha, María Lúcia. História da Educação e da Pedagogia, geral e do Brasil. São Paulo: Moderna, 2008.

Araújo, José Carlos Souza de. "Marcos filosóficos da modernidade em torno da educação da criança: antropologias da infância em disputa?". En A infância na modernidade: entre a educação e o trabalho, Editado por José Carlos.

Sousa de Araújo, Carlos Henrique de Carvalho, y Esmeralda Blanco Bolsonaro de Moura. Uberlândia: EDUFU, 2007, 182-183.

Buffa, Ester y Nosella, Paolo. Educação negada: introdução ao estudo da educação brasileira contemporânea. São Paulo: Cortez, 1991.

Cambi, Franco. História da pedagogia. São Paulo: UNESP, 1999. 
Constituição dos Estados Unidos do Brasil, de 10 de Novembro de 1937, (Brasil, 1937), http://www.planalto.gov.br/ccivil_03/Constituicao/Constituicao37.htm.

Cunha, Luís Antônio. O ensino profissional na irradiação do industrialismo. São Paulo: Flacso, 2000.

Decreto Lei no 7.566, de 23 de setembro de 1909, (Brasil, 1909), http://portal.mec.gov.br/ setec/arquivos/pdf3/decreto_7566_1909.pdf.

Faria Filho, Luciano Mendes de. Dos pardieiros aos palácios: cultura escolar e urbana em Belo Horizonte na Primeira República. Passo Fundo: UPF, 2002.

Franco, Luiz Antônio Carvalho, y Sauerbronn, Sidnei. Breve história da formação profissional no Brasil. São Paulo: CENAFOR, 1984.

Fonseca, Celso Suckow. Historia do Ensino Industrial no Brasil. Rio de Janeiro: Escola Técnica, 1961.

Gatti Júnior, Décio, y Pessanha, Eurize. "História da educação, instituições e cultura escolar: conceitos, categorias e materiais históricos”. En História da educação em perspectiva: ensino, pesquisa, produção e novas investigações, editado por Décio Gatti Júnior, Geraldo Inácio Filho. Campinas: Autores Associados, 2005,79-86.

Gonçalves Neto, Wenceslau. Estado e agricultura no Brasil. São Paulo: Hucitec, 1997.

Gonçalves Neto, Wenceslau, y Carlos Henrique Carvalho. "O nascimento da educação republicana: princípios educacionais nos regulamentos de Minas Gerais e Uberabinha (MG) no final do Século XIX”. En História da educação em perspectiva: ensino, pesquisa, producão e novas investigações, editado por Décio Gatti Júnior, Geraldo Inácio Filho. Campinas: Autores Associados, 2005, 264.

Magalhães, Justino. "A história das Instituições Educacionais em perspectiva". Em História da educaşão em perspectiva: ensino, pesquisa, produção e novas investigações, editado por Décio Gatti Júnior, Geraldo Inácio Filho. Campinas: Autores Associados, 2005,79.

Manfredi, Silvia. Educação Profissional no Brasil. São Paulo: Cortez, 2002.

Marx, Karl, y Engels, Friedrich. Crítica da Educaşão e do Ensino. Lisboa: Moraes Editores, 1978.

Nagle, Jorge. Educaşão e sociedade na primeira república. São Paulo: EPU, 1976.

Parecer CNE/CEB No 16/99 de 05 de outubro de 1999 (Brasil, 1999), http:/ /www.educacao.pr.gov.br/arquivos/File/pareceres/parecer161999.pdf.

Prado Júnior, Caio. História econômica do Brasil. São Paulo: Brasiliense, 1982.

Saviani, Demerval, Jane Soares de Almeida, Rosa Fátima de Souza, y Vera Teresa Valdemarin. O legado educacional do século XIX. Campinas: Autores associados, 2006.

Saviani, Demerval, Jane Soares de Almeida, Rosa Fátima de Souza, y Vera Teresa Valdemarin. O legado educacional do século XX. Campinas: Autores associados, 2004.

Schwartzman, Simon. Pobreza, exclusão social e modernidade: uma introdução ao mundo contemporâneo. São Paulo: Augurium, 2004.

Schwartzman, Simon, Bomeny, Helena Maria Bousquet, y Costa, Vanda Maria Ribeiro. Tempos de Capanema. São Paulo: Paz e Terra, 2000. 
Souza, Rosa Fátima de. Templos de Civilização: a implantação da escola primária graduada no Estado de São Paulo (1890/1910). São Paulo: EDUNESP, 1998.

Veiga, Cynthia Greive. "Escola Nova: a invenção de tempos, espaços e sujeitos”. En Lições de Minas: 70 anos da Secretaria de Educação, editado por Luciano Mendes de Faria Filho, Ana Maria Casasanta Peixoto. Belo Horizonte: Secretaria de Estado da Educação de Minas Gerais, 2003.

Veiga, Cynthia Greive. História da Educação. São Paulo: Ática, 2008.

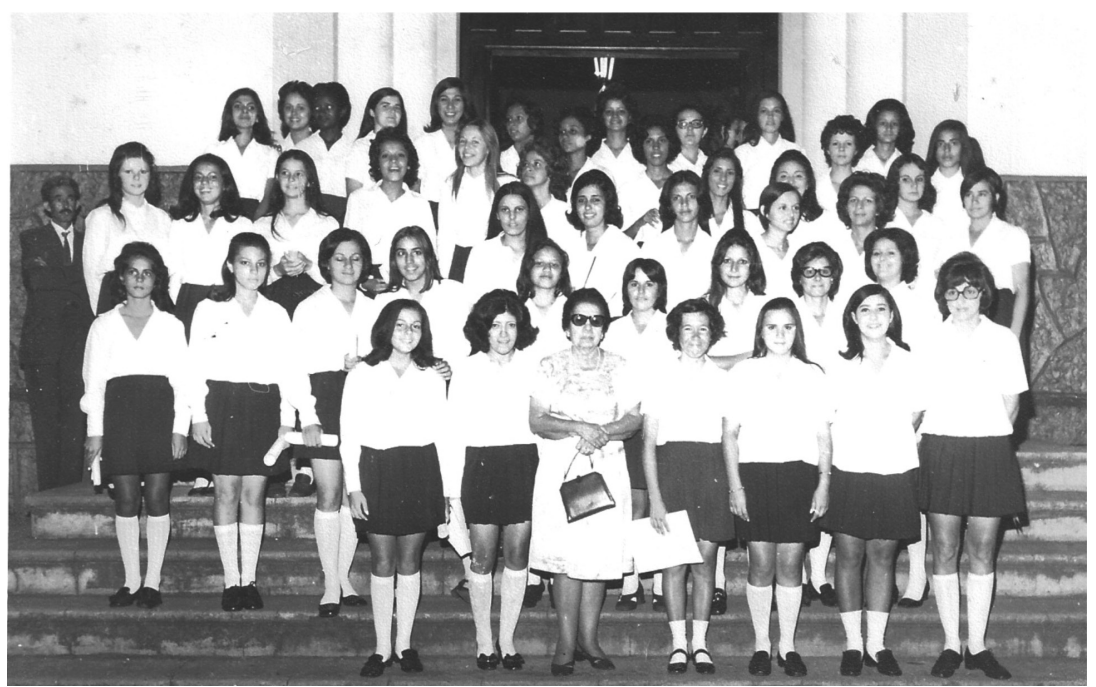

Fuente: Foto 2: Ensino profissionalizante brasileiro: Alunas de Economia Rural Doméstica Fonte: Arquivo do Instituto Federal do Triângulo Mineiro/Campus Uberaba (sem data) 


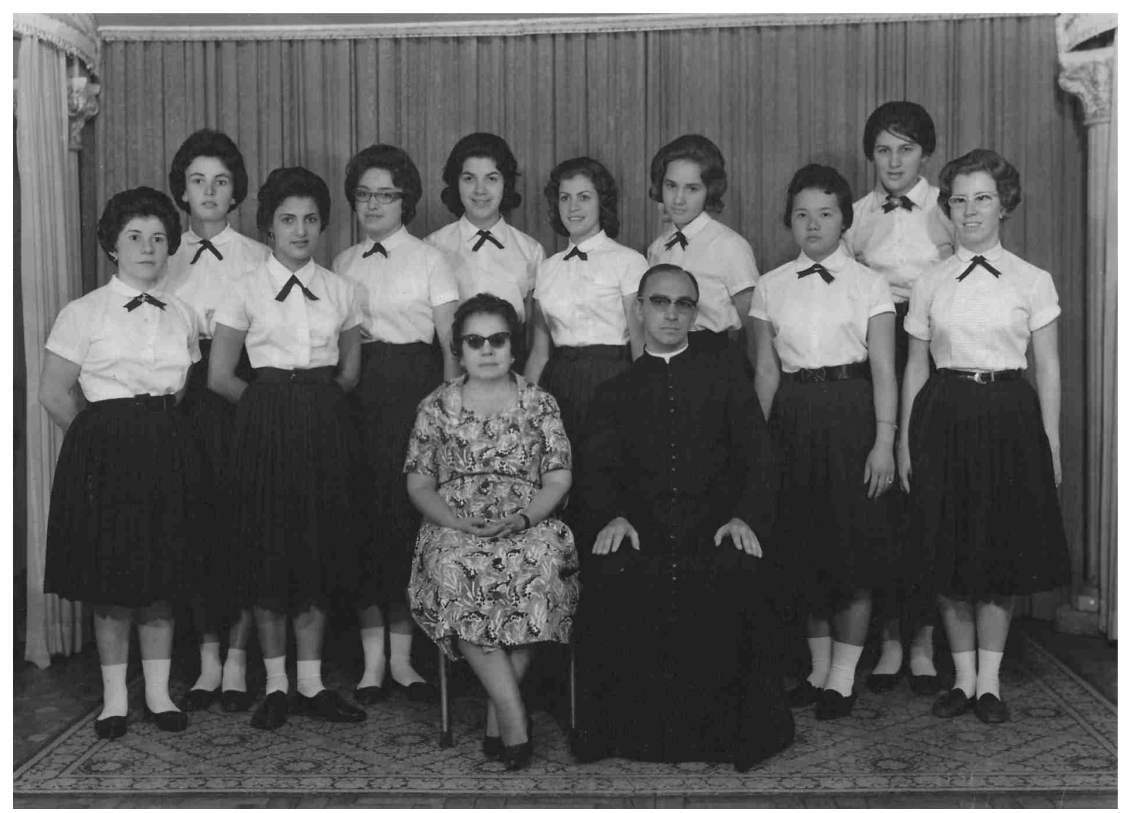

Fuente: Foto 1: Ensino profissionalizante brasileiro: Alunas de Economia Rural Doméstica Fonte: Arquivo do Instituto Federal do Triângulo Mineiro/Campus Uberaba (sem data)

\begin{tabular}{l|l|}
\hline Campos Ferreira, Nilce Vieira. "Educação secundária profissionalizante \\
Brasileira (1909 -1953)”. Revista Historia de la Educación Latinoamericana. Vol. 14 \\
No, 19, (2012)
\end{tabular}

